\title{
Impact of the adopted strategy on the result of multi-criteria analysis of technology solution based on AHP (BOCR)
}

\author{
Agnieszka Dziadosz ${ }^{1 *}$, Dominika Banach $^{1}$, Wiesław Meszek ${ }^{1}$ and Mariusz Rejment ${ }^{2}$ \\ ${ }^{1}$ Poznan University of Technology, Piotrowo 5 Street, 60-965 Poznan, Poland \\ ${ }^{2}$ Wroclaw University of Science and Technology, Wybrzeże Wyspiańskiego 27, 50-370 Wroclaw, \\ Poland
}

\begin{abstract}
The complexity of problems and the necessity to find a comprehensive approach to their solution favours the search for various methods that support the decision making process in the construction industry. At present, the multi-criteria methods lead the way. They enable the assessment of the problem in many aspects and with taking into account qualitative and quantitative data. Moreover, these methods do not limit the decision-maker in terms of the number of considered variants as well as the scope and the type of adopted assessment criteria. The aim of the article is to present the procedure of assessment of proposed building material solutions with taking into account the division of criteria due to their character - benefits (B) and costs (C). It was shown the dependence adopted by the decision maker strategy on the final ranking of solutions using the BOCR approach in the AHP method.
\end{abstract}

\section{Introduction}

The multi-criteria decision making methods are very useful support for solving complex problems. These problems often have to be assessed in a multi-aspect and comprehensive manner. It is not only important to identify the problem. It is also important to diagnose the proposed solutions by the decision maker for a given problem. The literature on the subject cites numerous examples of the use of the aforementioned methods, at the same time presenting their diversity, the procedure of aggregation of results, the possibility of combining by creating so-called "hybrids" [1-8]. These methods have many advantages, and one of the few disadvantages is the subjective judgment made by the decision maker. In the case of solving problems, in which we must take into account both qualitative and quantitative criteria, the basis for making the decision is the approximate result of the analysis and the initial ranking of variants. The authors of the paper checked the degree of dependence of the final ranking of variants of brickwork of the external, structural wall

\footnotetext{
* Corresponding author: agnieszka.dziadosz@put.poznan.pl
} 
from the strategy adopted by the decision maker, i.e. minimizing of costs or maximizing of profits based on the AHP method.

\section{AHP method and its BOCR extension}

This article presents a procedure based on the method of the Analytic Hierarchy Process (AHP), which takes into account the division of criteria into favourable and unfavourable from the decision-maker's point of view. The AHP method, developed by Thomas L. Saaty in the 1970s, is to rank the considered variants from the best to the worst [9]. The author of the AHP method introduced a 9-point scale for pairwise comparison, wherein the value of 1 means the equivalence of two criteria (factors, alternatives, etc.), and 9 means the absolute advantage of one criterion over the other. To facilitate the calculations, the considered pairs are set together in the matrix, comparing successively the elements from the first column with the elements of the top row.

However, the authors of the following works $[10,11]$ proposed the division of criteria by their character as well as by taken into account in the procedure of the criteria selection the criteria that are opposite to others. The criteria are ranked in 4 groups, namely: benefits (B), opportunities $(\mathrm{O})$, costs $(\mathrm{C})$ and risks $(\mathrm{R})$. For each of these groups, the rank is also assigned according to the AHP idea. Then, after performing the relevant calculations, the partial results are aggregated into the totality, i.e. in the final assessment of the construction investment in accordance with the method of results aggregation:

$\mathrm{bB}+\mathrm{oO}-\mathrm{Cc}-\mathrm{rR}$,

where:

b, o, c, r - are weights of groups,

while:

$\mathrm{B}, \mathrm{O}, \mathrm{C}, \mathrm{R}$ - are the data obtained from the analysis for each considered alternative obtained as a result of the AHP comparison.

We have 4 possibilities of combining the obtained results: B, O, C, R with appropriate normalized weights: $b, o, c, r$, namely:

$-\mathrm{bB}+\mathrm{oO}+\mathrm{c}(1 / \mathrm{C})+\mathrm{r}(1 / \mathrm{R})$,

$-b B+o O+c(1-C)+r(1-R)$,

$-\mathrm{bB}+\mathrm{oO}-\mathrm{cC}-\mathrm{rR}$.

However, the $\mathrm{BO} / \mathrm{CR}$ ratio (mentioned as the fourth option) does not take into account the normalized weights: $b, o, c, r$.

The procedure adopted for preparing variant of solutions:

1. Preparing of matrix of comparison in pairs for criteria in order to determine their mutual validity and for alternatives to a given criterion.

2. Pairwase comparison of alternatives with individual criteria according to the AHP idea.

3. Calculations of the vector of weights importance.

4. Calculation of $\lambda_{\max }$ (the maximum eigenvalue of the matrix).

5. Calculation of the consistency index $\left(\mathrm{CI}=\lambda_{\max }-\mathrm{n} / \mathrm{n}-1\right)$.

6. Choosing of the right value of the random consistency ratio (RI).

7. Calculation of the consistency ratio $(\mathrm{CR}=\mathrm{CI} / \mathrm{RI})$.

8. Checking of the consistency of the pairwise comparison matrix (if the comparisons in the matrix are consistent or not; the inconsistency of the matrix is allowed to be $-0,1 \mathrm{CR}<0,1$ ).

9. Aggregation of results according to the first or the second method:

$$
b * B+o * O+c * \frac{1}{C}+r * \frac{1}{R}
$$




$$
b * B+o * O+c *(1-\mathrm{C})+r *(1-R)
$$

\section{Case study - construction layer of wall}

\subsection{Proposed variants of building material solutions}

Analyzing the design documentation, the authors have proposed 3 variants of making the construction layer of a 3-layered exterior wall for a single-family building (Table 1). The quantity of brickwork (calculated in the bill of quantities) for the construction layer was $204,27 \mathrm{~m} 2$.

Table 1. Analyzed variants - building material

\begin{tabular}{|c|c|}
\hline Symbol & Variant \\
\hline $\mathrm{P}$ & Ceramic block Porotherm 25 Dryfix \\
\hline $\mathrm{Y}$ & Aerated concrete block Ytong Forte PP 2,5/0,4 \\
\hline $\mathrm{S}$ & Silicate block Silka E 24 \\
\hline
\end{tabular}

\subsection{Estimation criteria}

In the presented example, the authors have done the building material solutions assessment according to the classical AHP approach and after considering the BOCR development due to two groups of criteria: benefits - B and costs - C (Table 2 and Table 3). The application of the AHP method was dictated by its numerous advantages, i.e.:

- arrangement of factors, criteria and variants,

- the possibility of using quantitative and qualitative criteria,

- easy to understand course of proceedings,

- flexible model for a wide range of multi-criteria problems,

- no need to use specialized software,

- application of many criteria in order to make decision - multi-dimensionality of the problem.

Table 2. Selection criteria for Benefit (B)

\begin{tabular}{|c|c|}
\hline Symbol & Criteria \\
\hline KB1 & Overall heat transfer coefficient $-\mathrm{U}[\mathrm{W} / \mathrm{m} 2 \mathrm{~K}]$ \\
\hline $\mathrm{KB} 2$ & Sound insulation \\
\hline KB3 & Compressive strength \\
\hline
\end{tabular}

Table 3. Selection criteria for Costs (C)

\begin{tabular}{|c|c|}
\hline Symbol & Criteria \\
\hline $\mathrm{KC} 1$ & Building material purchase cost \\
\hline
\end{tabular}




\begin{tabular}{|c|c|}
\hline KC2 & Transport costs \\
\hline KC3 & Labour cost \\
\hline
\end{tabular}

\subsection{Evaluation and analysis of results}

The assessment of variants for benefits and costs is presented in Figure 1 and Figure 2 as well as in Table 4 without taking into account weights for the adopted strategies: maximizing of profit or minimizing of costs.

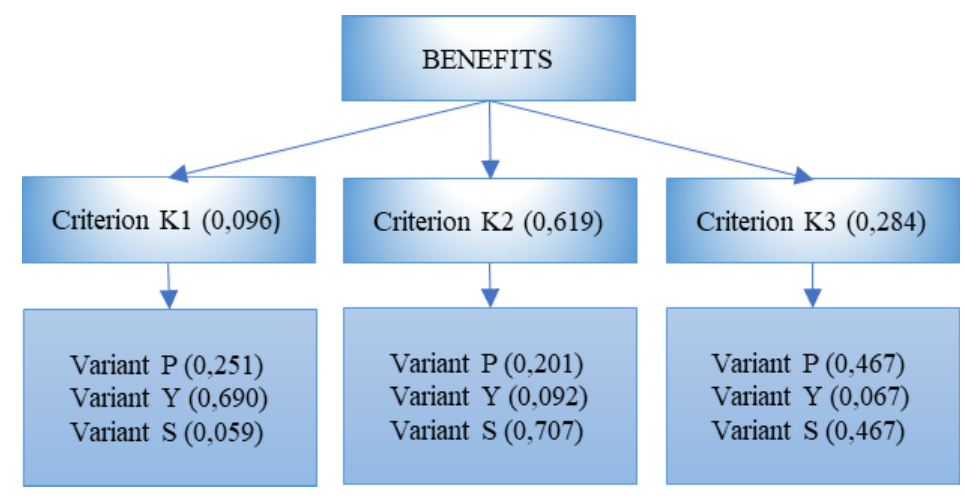

Fig. 1 Summary of results for benefits

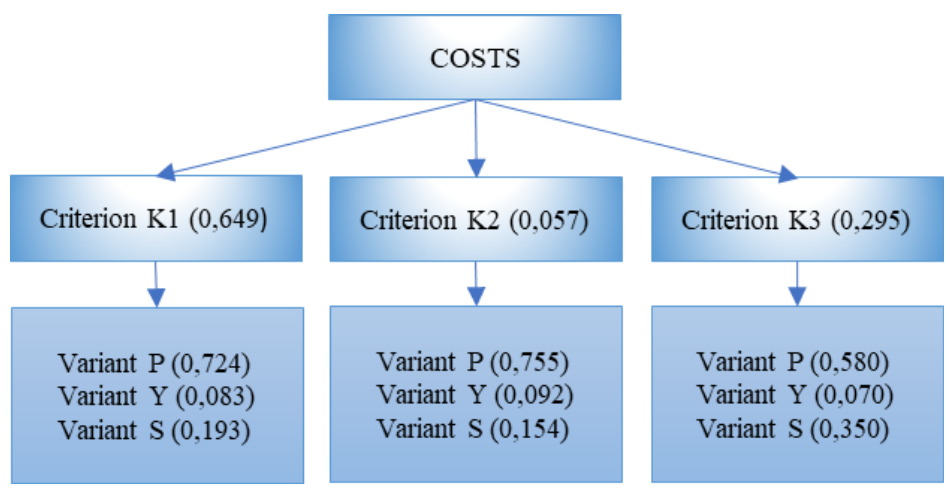

Fig. 2. Summary of results for costs

Table 4. Summary of results for benefits and costs

\begin{tabular}{|c|c|c|}
\hline $\begin{array}{c}\text { Building } \\
\text { material }\end{array}$ & Benefits & Costs \\
\hline $\mathrm{P}$ & 0,282 & 0,683 \\
\hline $\mathrm{Y}$ & 0,142 & 0,080 \\
\hline $\mathrm{S}$ & 0,576 & 0,237 \\
\hline
\end{tabular}


For the construction layer, the optimal solution, from the benefit perspective, was the variant of the wall made of silicate blocks - Silka, and from the cost perspective it was a variant of ceramic blocks - Porotherm. The introduction of the scenarios with weights has significantly changed the ranking. For the first equation, the best solution was made of aerated concrete blocks - Ytong, for both benefits and costs. For the second equation, due to the benefits, the optimal variant was silicate blocks - Silka, due to the costs - aerated concrete blocks Ytong (Tables 6, 7 and Figures 3, 4). In order to aggregate the results of the BOCR analysis, a scenario for the values of weights $b$ and $c$ was prepared (Table 5).

Table 5. Scenarios of weight values: $b$ and $c$

\begin{tabular}{|c|c|c|c|c|c|c|c|c|c|}
\hline & \multicolumn{10}{|c|}{ Scenarios } \\
\cline { 2 - 10 } & $9 / 1$ & $7 / 1$ & $5 / 1$ & $3 / 1$ & $1 / 1$ & $1 / 3$ & $1 / 5$ & $1 / 7$ & $1 / 9$ \\
\hline $\mathrm{b}$ & 0,900 & 0,875 & 0,833 & 0,750 & 0,500 & 0,250 & 0,167 & 0,125 & 0,100 \\
\hline $\mathrm{c}$ & 0,100 & 0,125 & 0,167 & 0,250 & 0,500 & 0,750 & 0,833 & 0,875 & 0,900 \\
\hline
\end{tabular}

Table 6. Analysis of results depending on the adopted weight scenario for the first equation

\begin{tabular}{|c|c|c|c|c|c|c|c|c|c|}
\hline \multirow{2}{*}{} & \multicolumn{10}{|c|}{ Scenarios } \\
\cline { 2 - 10 } & $9 / 1$ & $7 / 1$ & $5 / 1$ & $3 / 1$ & $1 / 1$ & $1 / 3$ & $1 / 5$ & $1 / 7$ & $1 / 9$ \\
\hline $\mathrm{P}$ & 0,400 & 0,429 & 0,479 & 0,577 & 0,873 & 1,168 & 1,267 & 1,316 & 1,346 \\
\hline $\mathrm{Y}$ & 1,378 & 1,687 & 2,207 & 3,233 & 6,323 & 9,413 & 10,439 & 10,959 & 11,268 \\
\hline $\mathrm{S}$ & 0,941 & 1,032 & 1,185 & 1,487 & 2,398 & 3,308 & 3,611 & 3,764 & 3,855 \\
\hline
\end{tabular}

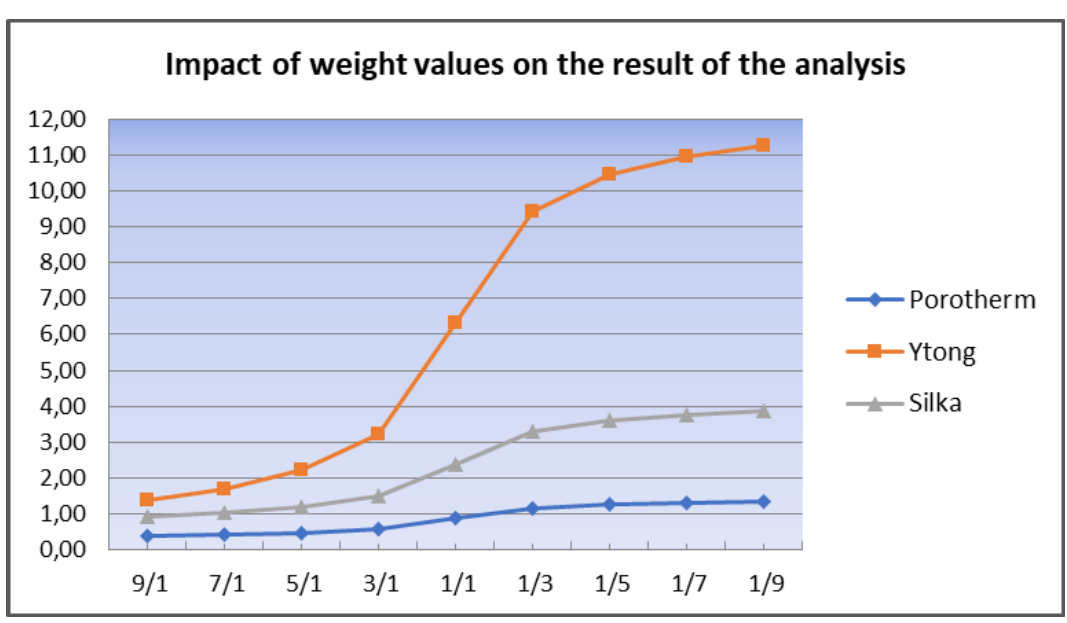

Fig. 3. The influence of weight values on the result of the analysis for the first equation

Analyzing the impact of weight values on the final result, it can be seen that in the case when for the decision-maker, the benefits are more important, the differences between options are convergent and there is not much variation between the alternatives from the 
benefits perspective. The optimal solution would be aerated concrete blocks Ytong. Other variants are classified lower in the chart than aerated concrete blocks Ytong.

If, however, the interest is increased from the cost perspective, the discrepancy between the variants is significant and then the best solution would be a variant with aerated concrete blocks Ytong. The other two variants slightly increase compared to the beginning.

Table 7. Analysis of results depending on the adopted weight scenario for the second equation

\begin{tabular}{|c|c|c|c|c|c|c|c|c|c|}
\hline & \multicolumn{10}{|c|}{ Scenarios } \\
\cline { 2 - 10 } & $9 / 1$ & $7 / 1$ & $5 / 1$ & $3 / 1$ & $1 / 1$ & $1 / 3$ & $1 / 5$ & $1 / 7$ & $1 / 9$ \\
\hline $\mathrm{P}$ & 0,285 & 0,286 & 0,287 & 0,290 & 0,299 & 0,308 & 0,311 & 0,313 & 0,313 \\
\hline $\mathrm{Y}$ & 0,220 & 0,239 & 0,272 & 0,337 & 0,531 & 0,726 & 0,790 & 0,823 & 0,842 \\
\hline $\mathrm{S}$ & 0,595 & 0,600 & 0,607 & 0,623 & 0,670 & 0,716 & 0,732 & 0,740 & 0,744 \\
\hline
\end{tabular}

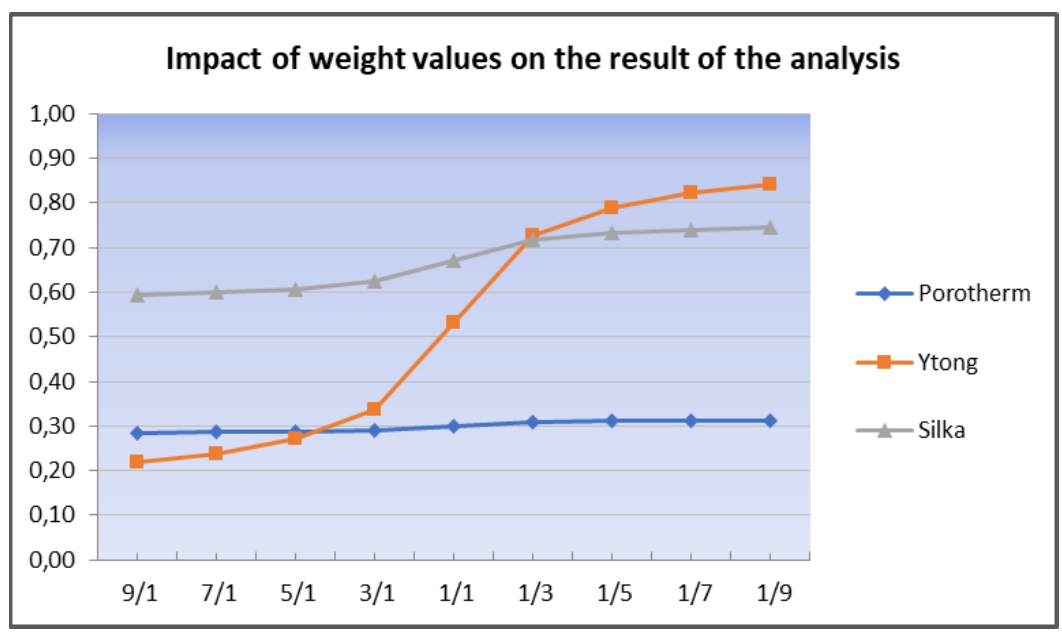

Fig. 4. The influence of weight values on the result of the analysis for the second equation

Analyzing the impact of weight values on the final result, it can be seen that in the case when for the decision-maker the benefits are more important, the differences between the variants are large, then silicate blocks Silka would be an optimal solution. Values for alternatives with ceramic blocks Porotherm and aerated concrete blocks Ytong are convergent.

If, however, the interest is increased from the cost perspective, the discrepancy between the variants varies dramatically and then the variant with aerated concrete blocks Ytong would be the best solution. However, the similar values are also occurring for the variant with silicate blocks Silka.

\section{Conclusions}

In conclusion, a comprehensive assessment of the considered alternatives allows the decision-maker to minimize the risk of making the wrong decision. The use of multicriteria methods allows avoiding randomness in the decision-making process. It also allows taking into account the requirements and preferences of the decision maker and allows to 
consider the problem in the multi-dimensional way. Using the development of the AHPBOCR method, it is possible to comprehensively analyze of variants with the isolation of those factors that are most important for the decision maker. It is worth emphasizing that the final result of the selection is influenced by the strategy adopted by a decision maker: maximizing of profit or minimizing of costs. As the presented example shows, the final ranking depends on the adopted weights for the assumed strategies, as well as depends on the method of the results aggregation.

The question of subjectivity of ratings remains with the use of multi-criteria methods. We need an approximate result more and more often, which is the premise for making a decision and a preliminary ranking of variants for solving the problem rather than giving the exact value.

\section{References}

1. R. Kozik, AIP Conf. Proc. 1863,1, 230016, ICNAAM 2016 (2017)

2. A.Dziadosz, Tech.Trans., (1-B), 41-51 (2008)

3. Gajzler M. A.Dziadosz, P.Szymański, Tech. Trans. (1-B), 2, 107, 71-84 (2010)

4. A.Dziadosz, M.Rejment (1-B), 5, 221-228 (2014)

5. R.Kozik, AIP Conf. Proc., ICNAAM 2015 (2016)

6. A. Dziadosz, Proc. 5th Nordic Conf. on Constr. Econ.and Organ., 1, 213-222 (2010)

7. H. Hashemi, S. M. Mousavi, E. K. Zavadskas, A. Chalekaee, Z.Turskis, Sustain. 10 (5), 1635 (2018)

8. M. Gajzler, K.Zima, Inter. J. of Civil Eng., 15 (5), 641-52 (2017)

9. T.L. Saaty, J. of Sys. Scien. and Sys. Eng., 13, 1, 1-35 (2004)

10. T.L.Saaty, Y. Choy, Soc.-Econ.Plan. Scien., 35, 243-252 (2001)

11. T.L. Saaty, M. Ozdemir, Math. Comp. Model., 37, 1063-1075 (2003) 